\title{
Hoffa's Fracture with Associated Injuries Around the Knee Joint: An Approach to a Rare Injury
}

Subodh Pathak ${ }^{1}$, Abhijeet Salunke ${ }^{2}$, Shailesh Karn ${ }^{3}$, Harish V K. Ratna ${ }^{1}$, Praveen S. Thivari ${ }^{1}$, Sarthak Sharma ${ }^{1}$, Sabyasachi Jena ${ }^{1}$

1. Orthopedics, Maharishi Markandeshwar (deemed to be University), Ambala, IND 2. Orthopedics, Gujarat Cancer Research Institute, Ahmadabad, IND 3. Orthopedics / Orthopedic Surgery / Orthopedic Oncology, Maharishi Markandeshwar (deemed to be University), Ambala, IND

Corresponding author: Subodh Pathak, drsubodh08@gmail.com

\begin{abstract}
Fractures of the distal femur typically occur in the axial and sagittal planes. A Hoffa fracture is a coronal plane fracture of the femoral condyle, which accounts for $8.7 \%$ to $13 \%$ of distal femoral fractures. It is usually associated with other injuries around the knee joint and hence is often missed. We conducted a comprehensive systematic review of papers published in the English language using PubMed, Web of Science, Scopus, and the Cochrane Database, which reported Hoffa's fracture associated with other injuries around the knee joint. We selected 11 eligible papers for final analysis and review. These papers had 12 patients with Hoffa's fracture, with associated injuries around the knee joint. The associated injuries with Hoffa's fracture were in the ipsilateral distal femur, proximal tibia fractures, patellar dislocation, patella fracture, and patellar tendon incarceration. The management principles for Hoffa's fracture with associated injuries around the knee joint are: having a high clinical index of suspicion for these injuries, obtaining all trauma series radiographs and computed tomography of the knee, achieving complete articular incongruity, and restoring the functions of the knee joint.
\end{abstract}

Categories: Orthopedics, Trauma

Keywords: hoffa's fracture, patellar dislocation, intercondylar eminence, supracondylar femur, tibia fracture, patella fracture

\section{Introduction}

Hoffa's fracture is a coronal-oriented fracture of the distal femur with the fracture line extending through the medial condyle, lateral condyle, or bicondylar region [1-3]. This fracture presents commonly as an isolated fracture and, in rare instances, it is associated with other injuries around the knee joint. The presence of Hoffa's fracture warrants proper clinical evaluation and treatment planning for the patient, as these fractures are associated with high-velocity injuries. These injuries usually affect the younger population after a road traffic accident. The diagnosis of Hoffa's fracture is challenging and needs strong suspicion. The associated injuries with Hoffa's fracture are in the ipsilateral distal femur, proximal tibia fractures, patellar dislocation, patella fracture, and patellar tendon incarceration. The trauma series radiographs of the knee joint with anteroposterior, lateral, oblique, and skyline views are important for evaluation. Computed tomography (CT) is an important tool for the assessment of Hoffa's fracture, as these fractures are often missed on plain radiographic evaluation [3]. Magnetic resonance imaging (MRI) and CT of the knee joint plays a vital role in assessing the articular surface congruity of the distal femur and proximal tibia. Hoffa's fracture is treated with the principles of treatment of intraarticular fractures, with proper articular surface realignment. Closed reduction of a dislocated patella with Hoffa's fracture in an emergency room and field triage should be avoided to prevent patellar tendon incarceration, patellar tendon rupture, and osteochondral damage. We have conducted a systematic review of Hoffa's fracture with associated injures around the joint and have suggested a proper clinical approach for the treatment of these injuries.

\section{Materials And Methods}

We conducted a comprehensive systematic review of papers published in the English language using PubMed, Web of Science, and Scopus, which reported Hoffa's fracture associated with other injuries around the knee joint. Literature search results for Hoffa's fracture and associated injuries around the knee joint were done with the keyword "Hoffa fracture." Search terms were broad to encompass all possibilities for applicable studies. The search for the studies in the database was performed on February 23, 2017. We did not place any restrictions on the date of publication. Fifty-six articles were identified from PubMed, 92 from Web of Science, and 39 from Scopus after the initial search (Figure 1). 


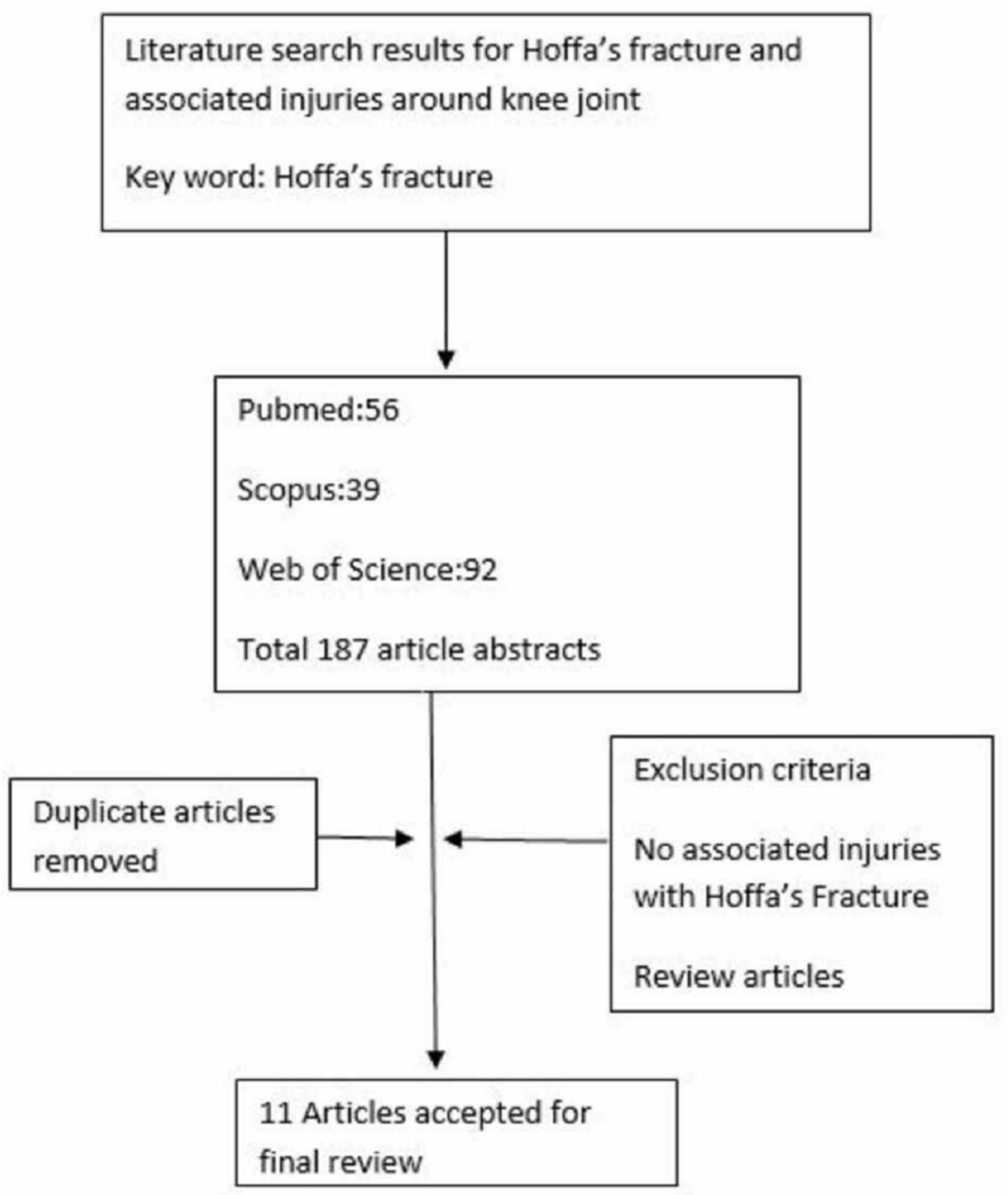

FIGURE 1: Literature search results for Hoffa's fracture and associated injuries around the knee joint

The 187 articles were identified and duplicated articles were removed, and we used the predefined inclusion and exclusion criteria. One-hundred seventy-six articles were excluded on the basis of title and abstract review. We finally selected 11 articles for the systematic review. The supplemental table in the Appendix shows the characteristics of the included studies. The studies that described patients with Hoffa's fracture and associated injuries around the knee joint were included in this review. The exclusion criteria included animal studies, review articles, pediatric fractures, and Hoffa's fractures without injuries around the knee joint.

\section{Results}

We selected 11 eligible papers for the final analysis and review. These papers had 12 patients with Hoffa's fracture, with associated injuries around the knee joint. The associated injuries with Hoffa's fracture are femoral shaft fractures, supracondylar femur fractures, knee dislocations, patellar tendon incarcerations, patella fractures, and patellar dislocation (as given in the supplemental table in the Appendix). Out of the 12 patients, $50 \%(n=6)$ patients had an injury to the patella or the extensor mechanism, making it the most common associated injury. The other common associated injury was a femoral shaft fracture, occurring in $33.34 \%(n=4)$.

Baker et al. in 2002 described a case of unicondylar Hoffa's fracture with a supracondylar fracture of the femur after a road traffic accident [4]. Calment et al. presented a case series of two cases of open bicondylar Hoffa's fracture with associated injuries around the knee joint following a road traffic accident [5]. The first case was a patellar tendon rupture with Hoffa's fracture and the patient was treated with fixation of the patellar tendon with non-absorbable suture material. The second case was a distal femur fracture and quadriceps tendon rupture and the patient was treated with cancellous screw fixation and fixation of the quadriceps tendon with non-absorbable suture material. Miyamoto et al. and Gong et al. described a case of 
a femoral shaft fracture with unicondylar Hoffa's fracture and the patient was treated with interlocking nailing and internal fixation, respectively [6-7]. Hoffa's fracture with associated tibia spine avulsion and posterior cruciate ligament rupture was treated with suture anchors for PCL fixation [8]. Bali et al. described a case of tibia spine avulsion and quadriceps tendon rupture and was treated with non-absorbable suture material [9]. A patella fracture with associated Hoffa's fracture is treated with tension band wiring [10-13]. Shetty et al. described a case of patellar tendon incarceration in Hoffa's fracture with an associated patellar fracture [10]. Vaishya et al. described a case of patellar dislocation with Hoffa's fracture following a household traumatic event [14]. In this case report, the diagnosis of Hoffa's fracture was missed at the initial stage in the primary hospital and a closed reduction of patellar dislocation was performed, resulting in an avulsion patellar fracture. Subsequently, an open reduction of Hoffa's fracture was performed with lateral patellar retinaculum repair. Hoffa's fracture with femur shaft and tibia fracture was described by Jain et al. and the patient was treated with internal fixation [15]. Femoral-sided fracture and dislocation of the knee joint were described by Schenck et al. [16]. Nietosvaara et al. described the association of osteochondral fractures with patellar dislocation [17]. Acute dislocations of the patella without associated injuries are treated with a closed reduction method. The technique of closed reduction of the patella involves two steps, i.e., the gradual extension of the knee joint and manual pressure over the lateral aspect of the patella. Closed reduction of a dislocated patella without proper clinical examination and radiological assessment in the emergency room and field triage is not recommended, as it can lead to patellar tendon incarceration, patellar tendon rupture, and osteochondral damage, patella fracture [14,17-19]. Post-traumatic patella dislocation is associated with osteochondral or chondral injuries [17-19].

\section{Discussion}

A coronal-oriented fracture of the distal femur with the fracture line extending through the femoral condyle was described first in 1904 by Hoffa [1]. In 1946, Smillie et al. described these fractures in the review of injuries around the knee joint [2]. The incidence of Hoffa's fracture is $0.65 \%$ of all femoral fractures [3]. The femoral condyles are anatomically in line with the front of the femoral shaft and project backward beyond the shaft, similar to the shape of the alphabet "J." The medial condyle is larger, more curved, and projects further than the lateral condyle, accounting for the angle between the femur and the tibia [20]. The medial condyle is inferior to the lateral condyle by an average of $7.14 \mathrm{~mm}$ on the right side and $7.06 \mathrm{~mm}$ on the left side in relation to the femoral shaft axis [21].

\section{Mechanism of Injury and Classification of Hoffa's Fracture}

The normal riding posture of the motorcyclist involves sitting with the knee flexed at or beyond 90 degrees. The lateral femoral condyle receives a direct impact during road traffic accidents because the knee joint is flexed and abducted while driving a two-wheeler vehicle. The mechanism of injury of Hoffa's fracture is the direct impact of the flexed knee joint to the ground surface or due to simultaneous vertical shear and twisting forces [6-9]. The majority of these injuries are due to motor vehicle accidents and are rarely associated with trivial injuries [11,22-23]. Hoffa's fractures are classified as AO type 33 B3 fractures based on partially intra-articular localization of the fracture into unicondylar and bicondylar fractures [24]. The anatomical classification is based on the localization of the fracture line into three types, i.e., lateral Hoffa's fracture and bicondylar Hoffa's fracture and medial Hoffa's fracture. The lateral Hoffa's fracture and bicondylar Hoffa's fracture are common as compared to the medial Hoffa's fracture [11-12]. In 1978, Letenneur et al. described the classification of Hoffa's fracture based on the distance of the fracture line from the posterior femoral cortex into three types [25].

\section{Clinical Examination and Radiological Evaluation}

Hoffa's fracture evaluation should be a routine part of the lower-limb and pelvis examination with or without injury [26]. A patient with Hoffa's fracture presents after sustaining a high-velocity road traffic accident, and rarely due to trivial trauma, with swelling and pain around the knee joint and difficulty in walking. A detailed examination of the affected leg is necessary during the triage and emergency department assessment. The radiographic evaluation includes anteroposterior, lateral, oblique, and tangential patellar and tunnel views for the diagnoses of associated injuries around the knee joint [24$25,27]$. The clinical features suggestive of a distal femur fracture are swelling and tenderness around the knee joint. The diagnosis of Hoffa's fracture is challenging and needs strong suspicion after a clinical examination of the patient. Interpretation of an anteroposterior radiograph of the knee joint is difficult because Hoffa's fracture is obscured due to the intact anterior part of the femoral condyles [2]. An oblique radiograph is the most important radiograph in the evaluation of Hoffa's fracture, as it provides proper orientation of the fracture line [24,27]. The radiographs of the femur and tibia must be considered during the evaluation of patients with other suspected injuries. A CT scan of the knee joint provides orientation of the fracture line, with subchondral and intraarticular fracture fragments helping in preoperative planning (Figures 2-3) [24,27]. 


\section{Cureus}

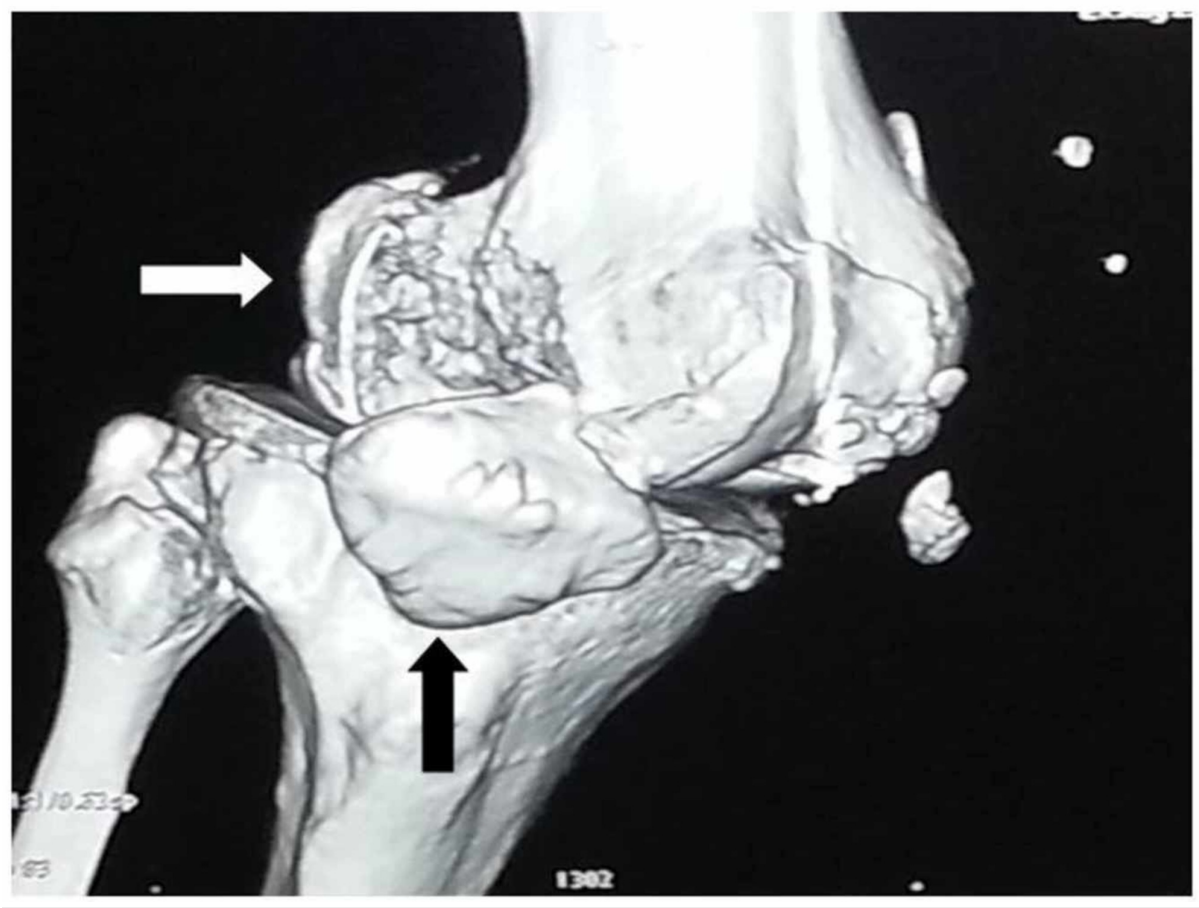

FIGURE 2: 3-D computed tomography showing Hoffa's fracture (white arrow) with patella dislocation (black arrow)

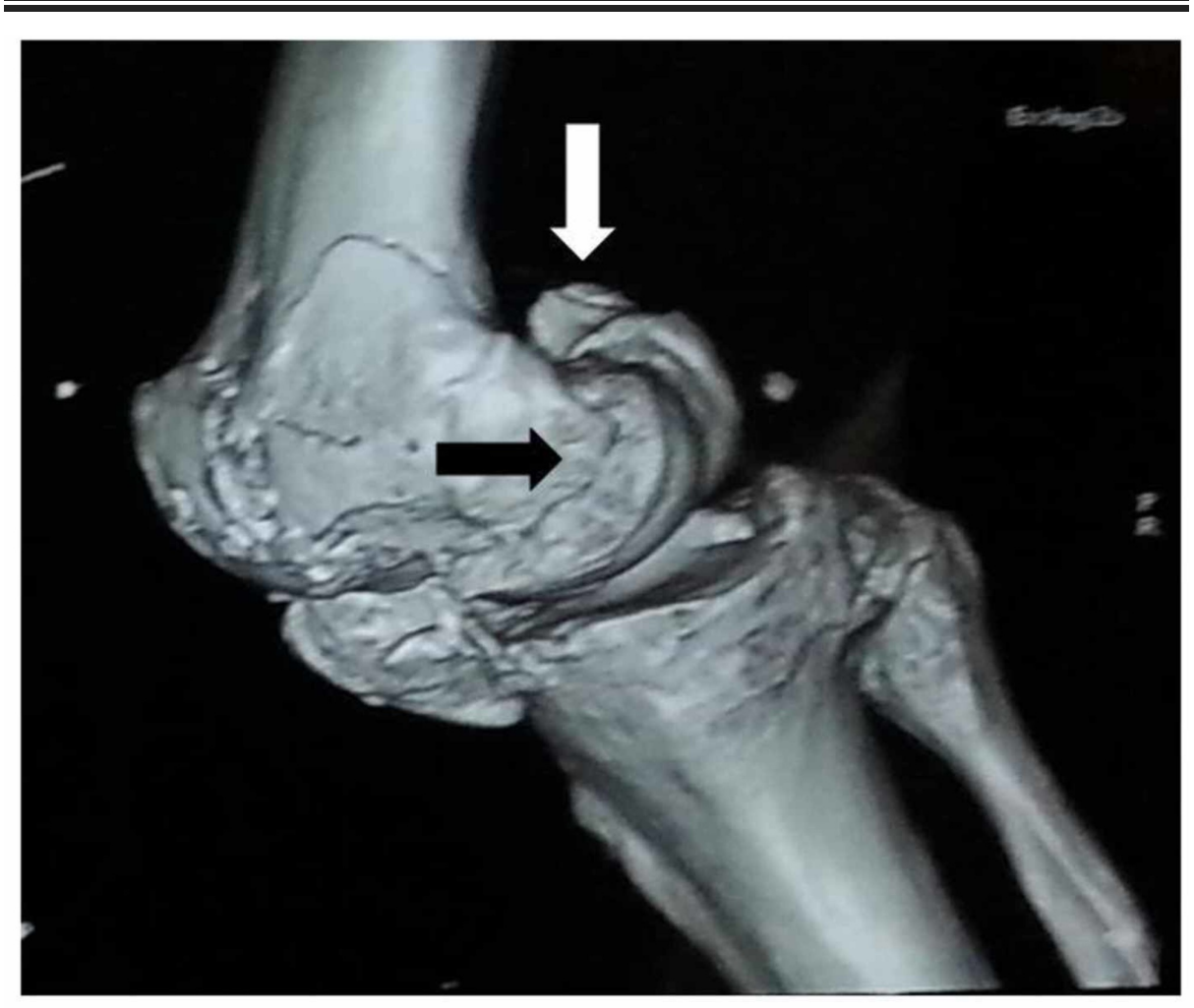

FIGURE 3: 3-D computed tomography showing bicondylar Hoffa's fracture: medial condyle (black arrow) and lateral condyle fracture (white arrow)

Magnetic resonance imaging can be used for the assessment of patellar tendon integrity during patellar tendon incarceration into Hoffa's fracture. 


\section{Cureus}

Hoffa's fractures are difficult to manage because the entire fragment may be covered by articular cartilage and may be devascularized. The surgical approach to these complex fractures and associated injuries and fractures is varied according to the pattern of injuries. Lateral Hoffa's fractures are approached through a lateral incision; a bicondylar Hoffa's fracture may require a medial and lateral double incision with tibial tubercle osteotomy [6-9,28-29]. A medial Hoffa's fracture can be approached through a medial parapatellar arthrotomy or subvastus approach $[28,30]$. Non-displaced Hoffa's fractures can be treated non-operatively; displaced fractures require surgical fixation in the form of cancellous lag screws or a buttress plate [27-28]. The screws are inserted down to the subchondral bone well beneath the surface of articular cartilage [27]. Postoperative anteroposterior, lateral, and oblique radiographs of the knee joint are used to assess the screw position and the reduction of the articular congruity of the knee joint. Postoperative management includes proper physiotherapy and knee mobilization exercises to achieve the full range of movement of the knee joint and proper function of the leg. Continuous passive motion exercises could be started on the third postoperative Day 1 to prevent knee stiffness and partial weight-bearing can be started as per the adequacy of surgical fixation and associated injuries. The complications of Hoffa's fracture are post-traumatic arthritis, axial mal-alignment, instability, and knee stiffness. The complications of this fracture, i.e., malunion and post-traumatic arthritis, can lead to early degenerative changes and loss of function. Osteochondral fragments in the knee joint can cause recurrent patellar dislocation or subluxation [17,19]. A patella fracture is an associated complication due to the closed reduction of the patellar dislocation with Hoffa's fracture [14].

\section{Conclusions}

Hoffa's fracture with associated injuries around the knee joint is an uncommon injury that has a high potential for missed diagnosis and improper treatment. An oblique view along with a lateral view is often required to diagnose the injury. The open reduction of patella dislocation, repair of the patellar and quadriceps tendon, fixation of the patella in the anatomical position, with the proper articular reconstruction of Hoffa's fracture, are the key steps of treatment of this injury.

\section{Appendices}




\section{Cureus}

\begin{tabular}{|c|c|c|c|c|c|}
\hline Author & $\begin{array}{l}\text { Year } \\
\text { Publication }\end{array}$ & $\begin{array}{l}\text { Associated } \\
\text { injury }\end{array}$ & $\begin{array}{l}\text { Mechanism } \\
\text { of Injury }\end{array}$ & Management & $\begin{array}{l}\text { Type of } \\
\text { fracture }\end{array}$ \\
\hline Baker [4] & 2002 & $\begin{array}{l}\text { Supracondylar } \\
\text { femur fracture }\end{array}$ & $\begin{array}{l}\text { Road traffic } \\
\text { accident }\end{array}$ & - & Unicondylar \\
\hline Calmet [5] & 2004 & $\begin{array}{l}\text { Patella tendon } \\
\text { rupture; Distal } \\
\text { femur and } \\
\text { quadriceps } \\
\text { tendon rupture }\end{array}$ & $\begin{array}{l}\text { Road traffic } \\
\text { accident; } \\
\text { Road traffic } \\
\text { accident }\end{array}$ & $\begin{array}{l}\text { Cancellous screw for Hoffa's fracture; Non- } \\
\text { absorbable sutures used for fixation of the patellar } \\
\text { tendon; Cancellous screw for Hoffa's } \\
\text { fracture; Nonabsorbable sutures used for fixation of } \\
\text { the quadriceps tendon }\end{array}$ & $\begin{array}{l}\text { Open } \\
\text { fracture } \\
\text { Bicondylar; } \\
\text { Open } \\
\text { fracture } \\
\text { Bicondylar }\end{array}$ \\
\hline Miyamoto [6] & 2006 & $\begin{array}{l}\text { Ipsilateral } \\
\text { femoral shaft } \\
\text { fracture }\end{array}$ & $\begin{array}{l}\text { Road traffic } \\
\text { accident }\end{array}$ & $\begin{array}{l}\text { Cortical screw for Hoffa's fracture; Interlocking } \\
\text { nailing for femur fracture }\end{array}$ & Unicondylar \\
\hline Ocguder [8] & 2008 & $\begin{array}{l}\text { Tibial spine } \\
\text { avulsion and } \\
\text { PCL rupture }\end{array}$ & $\begin{array}{l}\text { Road traffic } \\
\text { accident }\end{array}$ & $\begin{array}{l}\text { Headless cancellous screws for Hoffa's fracture; } \\
\text { Suture anchor for PCL fixation }\end{array}$ & Unicondylar \\
\hline Shetty [10] & 2008 & $\begin{array}{l}\text { Patellar tendon } \\
\text { incarceration } \\
\text { Patella fracture }\end{array}$ & $\begin{array}{l}\text { Road traffic } \\
\text { accident }\end{array}$ & $\begin{array}{l}\text { Cancellous screw for Hoffa's fracture Tension band } \\
\text { wiring for patella fracture }\end{array}$ & Unicondylar \\
\hline Vaishya [14] & 2009 & $\begin{array}{l}\text { Patella } \\
\text { dislocation }\end{array}$ & $\begin{array}{l}\text { Trivial } \\
\text { trauma }\end{array}$ & $\begin{array}{l}\text { Emergency patellar reduction Cancellous screw for } \\
\text { Hoffa's fracture Patella fracture treated } \\
\text { conservatively }\end{array}$ & $\begin{array}{l}\text { Unicondylar } \\
\text { Avulsion } \\
\text { patellar } \\
\text { fracture }\end{array}$ \\
\hline Gong [7] & 2011 & $\begin{array}{l}\text { Femur shaft } \\
\text { fracture }\end{array}$ & $\begin{array}{l}\text { Road traffic } \\
\text { accident }\end{array}$ & $\begin{array}{l}\text { Cancellous screw for Hoffa's fracture; Internal } \\
\text { fixation of femur fracture }\end{array}$ & Unicondylar \\
\hline Jain A [14] & 2012 & $\begin{array}{l}\text { Femur shaft and } \\
\text { Tibia fracture }\end{array}$ & $\begin{array}{l}\text { Road traffic } \\
\text { accident }\end{array}$ & $\begin{array}{l}\text { Cancellous screw for Hoffa's fracture Internal fixation } \\
\text { of femur and tibia fracture }\end{array}$ & Unicondylar \\
\hline Kini [12] & 2013 & $\begin{array}{l}\text { Extensor } \\
\text { mechanism }\end{array}$ & $\begin{array}{l}\text { Road traffic } \\
\text { accident }\end{array}$ & $\begin{array}{l}\text { Cancellous screw for Hoffa's fracture; Extensor } \\
\text { mechanism repair }\end{array}$ & $\begin{array}{l}\text { Open } \\
\text { fracture } \\
\text { Bicondylar }\end{array}$ \\
\hline Marzouki [13] & 2013 & Patella fracture & $\begin{array}{l}\text { Road traffic } \\
\text { accident }\end{array}$ & $\begin{array}{l}\text { Cancellous screw for Hoffa's fracture; Tension band } \\
\text { wiring for patella fracture }\end{array}$ & Unicondylar \\
\hline Mounasamy [11] & 2013 & Patella fracture & $\begin{array}{l}\text { Road traffic } \\
\text { accident }\end{array}$ & $\begin{array}{l}\text { Cannulated, headless screws for Hoffa's fracture; } \\
\text { Tension band wiring for patella fracture }\end{array}$ & $\begin{array}{l}\text { Open } \\
\text { fracture } \\
\text { Bicondylar }\end{array}$ \\
\hline
\end{tabular}

TABLE 1: Review of literature and study characteristics

\section{Additional Information}

\section{Disclosures}

Human subjects: Consent was obtained by all participants in this study. Animal subjects: All authors have confirmed that this study did not involve animal subjects or tissue. Conflicts of interest: In compliance with the ICMJE uniform disclosure form, all authors declare the following: Payment/services info: All authors have declared that no financial support was received from any organization for the submitted work. Financial relationships: All authors have declared that they have no financial relationships at present or within the previous three years with any organizations that might have an interest in the submitted work. Other relationships: All authors have declared that there are no other relationships or activities that could appear to have influenced the submitted work.

\section{References}

1. Hoffa A: Lehrbuch der Frakturen und Luxationen für Ärzte und Studierende [Book in German] . Enke, 1904.

2. Lewis SL, Pozo JL, Muirhead-Allwood WF: Coronal fractures of the lateral femoral condyle . J Bone Joint Surg Br. 1989, 71:118-120.

3. Manfredini M, Gildone A, Ferrante R, Bernasconi S, Massari L: Unicondylar femoral fractures: therapeutic 
strategy and long-term results. A review of 23 patients. Acta Orthop Belg. 2001, 67:132-138.

4. Baker BJ, Escobedo EM, Nork SE, Henley MB: Trauma cases from Harborview Medical Center. Hoffa fracture. A common association with high-energy supracondylar fractures of the distal femur. AJNR Am J Roentgenol. 2002, 178:994. 10.2214/ajr.178.4.1780994

5. Calmet J, Mellado JM, Forcada G, Giné J: Open bicondylar Hoffa fracture associated with extensor mechanism injury. J Orthop Trauma. 2004, 18:323-325. 10.1097/00005131-200405000-00012

6. Miyamoto R, Fornari E, Tejwani NC: Hoffa fragment associated with a femoral shaft fracture: a case report . J Bone Joint Surg Am. 2006, 88:2270-2274.

7. Yu-bao G, Chen Y, Shu-qiang LI, Jian-guo L, Xin QI, Qing-song L, Yuan T: Hoffa fracture associated with ipsilateral femoral shaft fracture: clinical feature and treatment. Chin J Traumatol. 2011, 14:376-378. 10.3760/cma.j.issn.1008-1275.2011.06.011

8. Ocguder A, Bozkurt M, Kalkan T, Ugurlu M, Kılıçarslan K: Hoffa fracture, eminentia fracture and posterior cruciate ligament damage: an unusual knee injury. Injury Extra. 2007, 39:88-91. 10.1016/j.injury.2007.08.027

9. Bali K, Mootha AK, Krishnan V, Kumar V, Rawall S, Goni V: A rare case of bicondylar Hoffa fracture associated with ipsilateral tibial spine avulsion and extensor mechanism disruption. Chin J Traumatol. 2011, 14:253-256. 10.3760/cma.j.issn.1008-1275.2011.04.012

10. Shetty GM, Wang JH, Kim SK, Park JH, Park JW, Kim JG, Ahn JH: Incarcerated patellar tendon in Hoffa fracture: an unusual cause of irreducible knee dislocation. Knee Surg Sports Traumatol Arthrosc. 2008, 16:378-381. 10.1007/s00167-007-0431-8

11. Mounasamy V, Hickerson L, Fehring K, Desai P: Open bicondylar Hoffa fracture with patella fracture: a case report and literature review. Eur J Orthop Surg Traumatol. 2013, 23:261-265. 10.1007/s00590-013-1194-1

12. Kini SG, Sharma M, Raman R: A rare case of open bicondylar Hoffa fracture with extensor mechanism disruption. BMJ Case Rep. 2013, 2013:bcr2013009541. 10.1136/bcr-2013-009541

13. Marzouki A, Zizah S, Benabid M, Elassil O, Lahrach K, Boutayeb F: A rare case of unicondylar medial Hoffa fracture associated with ipsilateral vertical patella fracture. J Clin Orthop Trauma. 2013, 4:102-105. 10.1016/j.jcot.2013.01.003

14. Vaishya R, Singh AP, Dar IT, Singh AP, Mittal V: Hoffa fracture with ipsilateral patellar dislocation resulting from household trauma. Can J Surg. 2009, 52:3-4.

15. Jain A, Agrawal P, Chadha M, Pankaj A, Min D: Hoffa fracture associated with femoral shaft and proximal tibial fractures: report of two cases. Chin J Traumatol. 2012, 15:367-369. 10.3760/cma.j.issn.10081275.2012.06.011

16. Schenck RC, McGanity PLJ, Heckman JD: Femoral-sided fracture-dislocation of the knee. J Orthop Trauma. 1997, 11:416-421. 10.1097/00005131-199708000-00007

17. Nietosvaara Y, Aalto K, Kallio PE: Acute patellar dislocation in children: Incidence and associated osteochondral fractures. J Pediatr Orthop. 1994, 14:513-515. 10.1097/01241398-199407000-00018

18. Arendt EA, Fithian DC, Cohen E: Current concepts of lateral patella dislocation . Clin Sports Med. 2002, 21:499-519. 10.1016/s0278-5919(02)00031-5

19. Cash JD, Hughston JC: Treatment of acute patellar dislocation. Am J Sports Med. 1988, 16:244-249. 10.1177/036354658801600308

20. Li K, Langdale E, Tashman S, Harner C, Zhang X: Gender and condylar differences in distal femur morphometry clarified by automated computer analyses. J Orthop Res. 2012, 30:686-692. 10.1002/jor.21575

21. Singh P, Aggarwal NK, Singh KD, Sapra A: Superio-inferior relationship between medial and lateral femoral condyles. J Anat Soc India. 2001, 50:131-133.

22. Mootha AK, Gupta AP, Saini R, Kumar V: Coronal fracture of medial femoral condyle: a case report and review of mechanism of injury. Internet J Orthop Surg. 2009, 14:[Epub].

23. Kumar R, Malhotra R: The Hoffa fracture: three case reports . J Orthop Surg. 2001, 9:47-51. $10.1177 / 230949900100900210$

24. Marsh JL, Slongo TF, Agel J, et al.: Fracture and dislocation classification compendium - 2007: Orthopaedic Trauma Association Classification, Database and Outcomes Committee. J Orthop Trauma. 2007, 47:1-133. 10.1097/00005131-200711101-00001

25. Letenneur J, Labour PE, Rogez JM, Lignon J, Bainvel JV: Hoffa's fractures. Report of 20 cases (author's transl) [Article in French]. Ann Chir. 1978, 32:213-219.

26. Zhou Y, Pan Y, Wang Q, Hou Z, Chen W: Hoffa fracture of the femoral condyle: injury mechanism, classification, diagnosis, and treatment. Medicine (Baltimore). 2019, 98:e14633. 10.1097/MD.0000000000014633

27. Thakar C: The Hoffa fracture - a fracture not to miss . Emerg Med J. 2010, 27:391-392. 10.1136/emj.2009.087213

28. Mak W, Hunter J, Escobedo E: Hoffa fracture of the femoral condyle. Radiol Case Rep. 2008, 3:231. 10.2484/rcr.v3i4.231

29. Nork SE, Segina DN, Aflatoon K, Barei DP, Henley BM, Holt S, Benirschke SK: The association between supracondylar-intercondylar distal femoral fractures and coronal plane fractures. J Bone Jt Surg Ser A. 2005, 87:564-569. 10.2106/JBJS.D.01751

30. Allmann KH, Altehoefer C, Wildanger G, Gufler H, Uhl M, Seif el Nasr M, Langer M: Hoffa fracture--a radiologic diagnostic approach. J Belge Radiol. 1996, 79:201-202. 